\title{
Chess endgame news: an Endgame challenge for neural nets
}

Article

Accepted Version

Haworth, G. (2019) Chess endgame news: an Endgame challenge for neural nets. ICGA Journal, 41 (3). p. 176. ISSN 1389-6911 doi: https://doi.org/10.3233/ICG-190109 Available at https://centaur.reading.ac.uk/86555/

It is advisable to refer to the publisher's version if you intend to cite from the work. See Guidance on citing.

Published version at: https://content.iospress.com/articles/icga-journal/icg 190109

To link to this article DOI: http://dx.doi.org/10.3233/ICG-190109

Publisher: The International Computer Games Association

All outputs in CentAUR are protected by Intellectual Property Rights law, including copyright law. Copyright and IPR is retained by the creators or other copyright holders. Terms and conditions for use of this material are defined in the End User Agreement.

\section{www.reading.ac.uk/centaur}

\section{CentAUR}

Central Archive at the University of Reading

Reading's research outputs online 


\title{
Chess Endgame News: an Endgame Challenge for Neural Nets
}

\author{
Guy Haworth ${ }^{1}$
}

Reading, UK

It is an exciting time for computer chess. One might have thought that things were plateauing out because even cloud-supported engines such as STOCKFISH are ELO-advancing only slowly. But then, along comes an exciting new, non-Shannon (1950) paradigm. David Silver's (2018) Deep Mind team successfully combine the ideas of neural-network-based learning and Monte-Carlo Tree Search in ALPHAZERO to find new competences in Go, Chess (Sadler and Regan, 2019) and Shogi.

Here, I pick out just three interesting aspects of this advance. First, ALPHAZERO is self-taught, an attractive minimalism providing maximum independence from suboptimal human ways of thinking. We first saw the benefits of this with the ATARI 2600's Breakout and other games (Mnih et al, 2013). Secondly, Deep Mind's openness has facilitated the creation by others of similar engines such as Goengine LEELAZERO and chess engine 'LC0' LEELA CHESS ZERO. Thirdly, the AlLIESTEIN hybrid engine for one is coming to the fore, aiming to synergise Shannon and MCTS approaches.

However, both LC0 and ALLIESTEIN seem weak, even rudderless, in the endgame. It is worth quoting Polya (1962): "If you can't solve a problem, then there is an easier problem you can solve: find it." Perhaps it is appropriate here to define a challenge for the deep-learning community, a research minimanifesto as it were. Train neural-networks on specific chess endgames (Haworth and Velliste, 1998) and benchmark their efficacy against the existing sub-8-man tables. How well will they play? Can we infer higher-order rules and guidelines for play from them?

\section{REFERENCES}

Haworth, G. $\mathrm{M}^{\mathrm{c}} \mathrm{C}$. and Velliste, M. (1998) Chess Endgames and Neural Networks. ICGA Journal, 21(4), 211-227. http://centaur.reading.ac.uk/4569/.

Mnih, V., Kavukcuoglu, K., Silver, D., Graves A., Antonoglou, I., Wierstra, D. and Riedmiller, M. (2013). Playing Atari with Deep Reinforcement Learning. arXiv:1312.5602v1 [cs.LG].

Polya, G. (1962). Mathematical Discovery on Understanding, Learning, and Teaching Problem Solving, Volume 1. Combined edition (1981), Wiley. ISBN 978-04-7108-975-9.

Sadler, M. and Regan, N. (2019). Game Changer: AlphaZero's Groundbreaking Chess Strategies and the Promise of AI. New in Chess. ISBN 978-90-5691-818-7.

Shannon, C. E. (1950). Programming a Computer for Playing Chess. The London, Edinburgh and Dublin Philosophical Magazine, 41(314), 256-275. https://doi.org/10.1080/14786445008521796.

Silver, D. et al (2018). A general reinforcement learning algorithm that masters chess, shogi, and Go through self-play. Science, 362(6419), 1140-4. doi: 10.1126/science.aar6404.

\footnotetext{
${ }^{1}$ Communicating author: g.haworth@ reading.ac.uk
} 